\title{
Synonymous single nucleotide polymorphism in arsenic $(+3)$ methyltransferase of the Western mosquitofish (Gambusia affinis) and its gene expression among field populations
}

\author{
Daesik Park $^{1} \cdot$ Catherine R. Propper ${ }^{2} \cdot$ Guangning Wang $^{2} \cdot{\text { Matthew C. Salanga } \mathbb{D}^{2}}^{2}$
}

Accepted: 22 February 2021 / Published online: 3 April 2021

(c) The Author(s) 2021

\begin{abstract}
Naturally occurring arsenic is toxic at extremely low concentrations, yet some species persist even in high arsenic environments. We wanted to test if these species show evidence of evolution associated with arsenic exposure. To do this, we compared allelic variation across 872 coding nucleotides of arsenic $(+3)$ methyltransferase $(a s 3 m t)$ and whole fish $a s 3 m t$ gene expression from three field populations of Gambusia affinis, from water sources containing low (1.9 ppb), medium-low (3.3 ppb), and high (15.7 ppb) levels of arsenic. The high arsenic site exceeds the US EPA's Maximum Contamination Level for drinking water. Medium-low and high populations exhibited homozygosity, and no sequence variation across all animals sampled. Eleven of 24 fish examined (45.8\%) in the low arsenic population harbored synonymous single nucleotide polymorphisms (SNPs) in exons 4 and/or 10. SNP presence in the low arsenic population was not associated with differences in as $3 m t$ transcript levels compared to fish from the medium-low site, where SNPs were noted; however, as $3 m t$ expression in fish from the high arsenic concentration site was significantly lower than the other two sites. Low sequence variation in fish populations from sites with medium-low and high arsenic concentrations suggests greater selective pressure on this allele, while higher variation in the low population suggests a relaxed selection. Our results suggest gene regulation associated with arsenic detoxification may play a more crucial role in influencing responses to arsenic than polymorphic gene sequence. Understanding microevolutionary processes to various contaminants require the evaluation of multiple populations across a wide range of pollution exposures.
\end{abstract}

Keywords Arsenic $\cdot a s 3 m t \cdot C y t 19 \cdot \operatorname{mosquitofish} \cdot$ Gambusia affinis $\cdot$ Arizona

\section{Introduction}

Rapid evolutionary responses to contaminants occur through both changes in gene sequence and gene expression. Adaptation to various contaminants has recently been reported through comparing mutations and expression of

Supplementary information The online version contains

supplementary material available at https://doi.org/10.1007/s10646021-02376-8.

Matthew C. Salanga

matthew.salanga@nau.edu

1 Division of Science Education, Kangwon National University, Chuncheon, Kangwon 24341, South Korea

2 Department of Biological Sciences, Northern Arizona University, Flagstaff, AZ 86011, USA specific genes associated with detoxification of pollutants across populations (Schlebusch et al. 2015; Reid et al. 2016; Gouin et al. 2019). Species introductions into contaminated areas provides an opportunity to evaluate early responses and/or adaptive processes to contaminants in the wild. Acquisition of new variations during the adaptation process at introduced sites often occur (Oziolor et al. 2019).

As well-known carcinogens, arsenics including inorganic arsenic (iAs), arsenate $\left(\mathrm{iAs}^{\mathrm{V}}\right)$, and arsenite (iAs ${ }^{\mathrm{III}}$ ) are widely found in drinking water, food, and other environmental sources. These compounds are involved in various negative impacts on health and welfare in humans and wildlife (Hughes et al. 2011; Carlin et al. 2016; Minatel et al. 2018). Vulnerable animal populations living in arsenic contaminated water face selective pressure to maintain alleles which encode arsenic detoxifying enzymes, such as As3mt, which metabolizes ingested arsenic into lowertoxicity compounds (Zhang et al. 2012). 


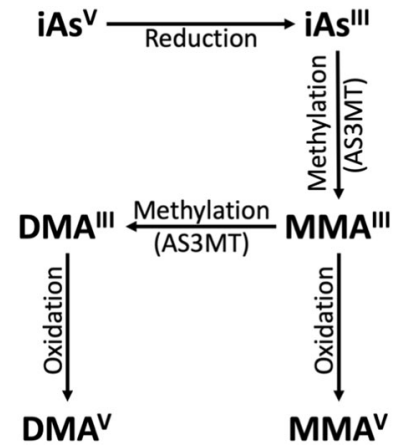

Fig. 1 Diagrammatic representation of arsenic metabolic pathways. After reduction of arsenate (iAs ${ }^{\mathrm{V}}$ ) into arsenite (iAs $\left.{ }^{\mathrm{III}}\right)$, it is metabolized to monomethylarsonic acid (MMA ${ }^{\mathrm{III}}$ or $\mathrm{MMA}^{\mathrm{V}}$ ) and subsequently to dimethylarsinic acid $\left(\mathrm{DMA}^{\mathrm{III}}\right.$ or $\mathrm{DMA}^{\mathrm{V}}$ ), a less toxic chemical, via methylation by arsenite $(+3)$ methyltransferase $(a s 3 m t)$ and oxidation. The diagram is based on Khairul et al. (2017) and Minatel et al. (2018)

Arsenic $(+3)$ methyltransferase (AS3MT; alias CYT19) is a key enzyme involved in the metabolic process of detoxifying $\mathrm{iAs}^{\mathrm{V}}$ and $\mathrm{iAs}{ }^{\mathrm{III}}$ through methylation of the arsenicals to less toxic arsenic forms of monomethylarsonic acids (MMA ${ }^{\mathrm{III}}$, $\mathrm{MMA}^{\mathrm{V}}$ ) and dimethylarsinic acids $\left(\mathrm{DMA}^{\mathrm{III}}, \mathrm{DMA}^{\mathrm{V}}\right.$ ) (Khairul et al. 2017; Minatel et al. 2018) (Fig. 1). Orthologues for $A S 3 M T$ are present across vertebrate clades, and its function in mitigating arsenic toxicity has been observed in multiple laboratory test species, including zebrafish (Hamdi et al. 2012; Bambino et al. 2018), Xenopus (Koch et al. 2015), and rodents (Waters et al. 2004; Coryell et al. 2018; Stýblo et al. 2019). Additionally, a bioinformatic query revealed uncharacterized orthologues in many more species, including birds and reptiles (Hunt et al. 2018) (Fig. S1).

In humans, decreased activity of AS3MT is linked to a SNP $(\mathrm{T}>\mathrm{C})$, resulting in a Met287Thr amino acid change (Drobna et al. 2009). Several other studies show allelic variation within human populations (Schlebusch et al. 2015; Apata and Pfeifer 2020), with polymorphisms detected in the AS3MT 5'-UTR that affect the conversion of inorganic arsenic to its organic forms (Wood et al. 2006; Valenzuela et al. 2009; Antonelli et al. 2014). Despite the widespread distribution of arsenic in nature, unlike studies in human populations, there are relatively few studies on whether mutations in AS3MT impact wildlife (Boyle et al. 2008; Ye et al. 2014; Hallauer et al. 2016). Such investigations in populations that have short generation times can lead to a better understanding of how AS3MT SNP distribution can impact AS3MT function as an evolutionary response to xenobiotic exposure.

Western mosquitofish (Gambusia affinis) have been widely used as a model animal to study the effects of various environmental pollutants (Turner 1942; Bortone and Davis 1994; Park et al. 2004). Western mosquitofish are native in the South-Central US and into Mexico, and are believed to have been introduced into Arizona in the early 1920s. They now inhabit 22 different Hydrologic Unit Code sites in the state (Dees 1961; Miller and Lowe 1967), though their population and genetic origins are undetermined. Surface waters in Arizona demonstrate considerable variation in arsenic contamination levels, with waterways below the current United States Environmental Protection Agency's drinking water limit of $10 \mathrm{ppb}$ (parts per billion), to stream and rivers containing arsenic concentrations well above $100 \mathrm{ppb}$ (Jones et al. 2020). Considering that various negative effects of arsenic have been reported in fish (Boyle et al. 2008; Hallauer et al. 2016), and that nuclear genes have shown rapid evolution within 80-90 years following the introduction in other fish populations (Dlugosch and Parker 2008), it is possible that adaptive selection to metabolize or detoxify arsenic effectively may have occurred in G. affinis.

In this study, we tested the hypotheses that the identity of as $3 m t$ allele variants and their expression correlate with arsenic levels in that fish's water resource. Like in human studies, we predict, that SNP containing as $3 m t$ alleles identified in G. affinis exposed to high arsenic will exhibit differences in frequencies related to their environmental arsenic exposure probability, and that expression of as $3 m t$ will track with arsenic levels in the water resources.

\section{Materials and methods}

\section{Collecting sites}

For the study, we collected Western mosquitofish (Arizona Game and Fish Department; LIC\#SP649802) at the outflow ditch of Bubbling Pond fish-hatchery (BP, 17 males, $34.45 \mathrm{~N},-111.53 \mathrm{E}$ ), Willow Lake (WL, 24 males, $34.36 \mathrm{~N}$, $-112.26 \mathrm{E})$, and the Salt River, just below Saguaro Lake (SR, 17 males, $33.33 \mathrm{~N},-111.32 \mathrm{E}$, Fig. 2) between March 30 and August 23, 2019 using dip nets. The fishes were euthanized in $0.04 \%$ buffered tricaine methanesulfonate (MS222, pH 7.0, CAS\# 886-86-2), individually frozen on dry ice in the field, brought to the lab, and stored at $-80^{\circ} \mathrm{C}$ until use. To avoid potential interference caused by females' reproductive status, we chose only males for further quantitative PCR. All protocols were approved under Northern Arizona University's Institutional Animal Care and Use Committee (IACUC Protocol \#19-013).

\section{Inductively coupled plasma mass spectrometry (adapted from Credo et al. 2019)}

For this study, arsenic levels were quantified at only one time point for each site. We collected two $500 \mathrm{ml}$ water samples from each of the three sites on December 4, 2019 in clean wide-mouth packers (\#05-719-149B, Fisher 
Scientific). $100 \mathrm{ml}$ of each water sample were filtered into two clean $50 \mathrm{ml}$ Falcon tubes using a $0.45 \mu \mathrm{m}$ Whatman uniflo syringe filter (\#09-928-061, Fisher Scientific) and a Norm-ject $30 \mathrm{ml}$ luer-lock pp/pe syringe (\#14-817-41, Fisher Scientific). The filtered water samples were kept ice cold while transporting to the laboratory, where they were stored at $4{ }^{\circ} \mathrm{C}$ until analysis. The water samples were acidified with concentrated trace metal nitric acid to a $\mathrm{pH}$ of approximately 2.0. Acidified samples were diluted $1: 10$ with $2 \%$ trace metal $\mathrm{HNO}_{3}$ and spiked with an internal standard (Iridium and Rhodium) at $1.0 \mathrm{ppb}$. Prepared samples (two for each site) were run in triplicate on a Thermo X-Series II Inductively Coupled Plasma Mass Spectrometer (ThermoFisher). In parallel, calibration standards (spiked with the internal standard) and a

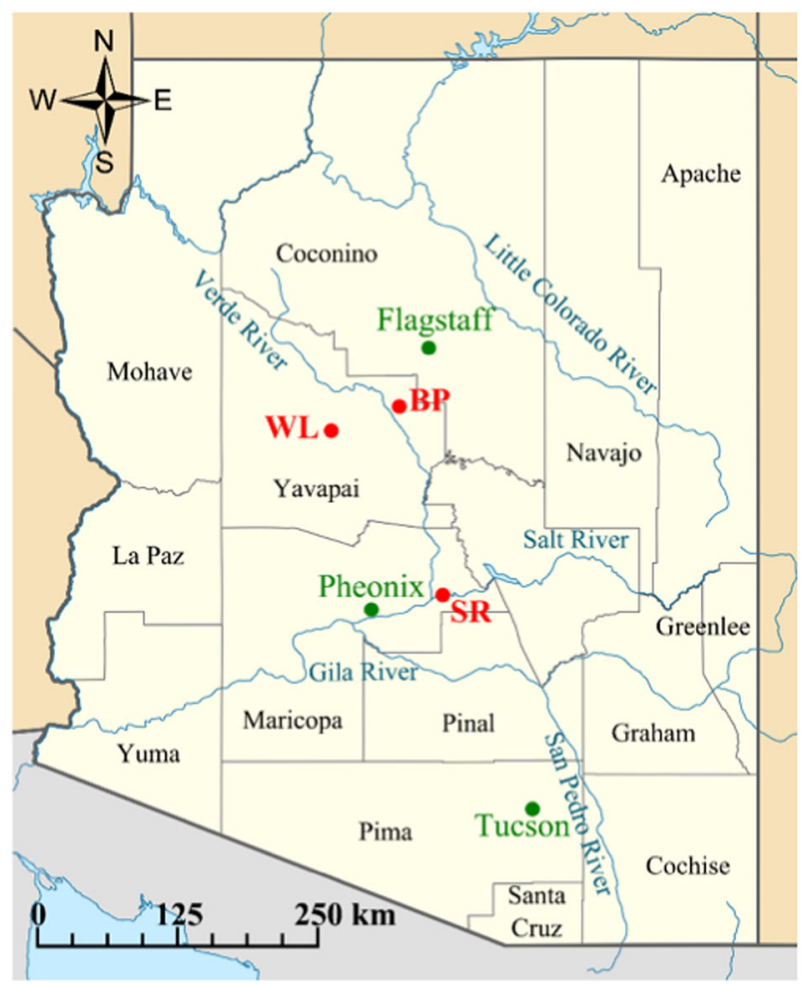

Fig. 2 Map of Arizona and collection sites for Western mosquitofish. BP Bubbling Pond fish-hatchery, WL Willow Lake, SR Salt River certified reference material (NIST 1640a - Trace Metals in Natural Waters) were also run. Dissolved arsenic concentrations at each site were determined by averaging arsenic levels from two samples.

\section{RNA isolation and CDNA synthesis}

To measure genotype specific as $3 m t$ gene expression, we isolated RNA from genotype verified individual fish for RNA isolation and gene expression analysis. Whole individuals were homogenized in 0.5-2 $\mathrm{ml}$ of TRIzol (\#15596026, ThermoFisher) using a PowerGen 125 homogenizer (\#NC0530997, Fisher Scientific) in microcentrifuge tubes. DNA-free total RNA was extracted from each sample using Direct-Zol RNA MiniPrep kit (\#R2050-51, Zymo Research) following the company's protocols. Isolated RNA concentration was quantified using a NanoDrop Lite (Thermo Scientific), inspected by gel electrophoresis for ribosomal RNA integrity, and cDNA was synthesized from $1 \mu \mathrm{g}$ of DNA-free total RNA using BioRad iScript cDNA synthesis kit (\#1708890, BioRad). Briefly, total reaction volume of $20 \mu \mathrm{L}$ containing $1 \mu \mathrm{g}$ of the extracted RNA was used, and the final mixture was incubated at $5 \mathrm{~min}$ at $25^{\circ} \mathrm{C}, 20 \mathrm{~min}$ at $46^{\circ} \mathrm{C}, 1 \mathrm{~min}$ at $95{ }^{\circ} \mathrm{C}$, and holding at $4{ }^{\circ} \mathrm{C}$ in a thermocycler (SimpliAmp, Applied Biosystems). Synthesized cDNA samples were stored at $-20^{\circ} \mathrm{C}$.

\section{PCR and allele sequencing}

For PCR amplification of as $3 m t$, we designed forward and reverse primers (Table 1) based on the G. affinis as $3 m t$ reference sequence obtained from Ensembl (ENSGAFG00000012739; Hunt et al. 2018), which consists of 1119 base pairs over 11 exons. One-twentieth of the total cDNA (1 ul) was used as template and amplified by Q5' High Fidelity DNA polymerase (\#M0491, New England BioLabs) in a $40 \mu \mathrm{l}$ reaction volume according to manufacturer's instructions. Briefly, the mixture was incubated at $10 \mathrm{~s}$ at $98{ }^{\circ} \mathrm{C}, 30 \mathrm{~s}$ at $58^{\circ} \mathrm{C}$, $45 \mathrm{~s}$ at $72^{\circ} \mathrm{C}$ for 35 cycles in a PCR thermocycler (SimpliAmp, Applied Biosystems). PCR amplicons were visualized by $1 \%$ agarose-gel and compared with a $2-\log$
Table 1 List of primers used for PCR and qPCR in Gambusia affinis

\begin{tabular}{llc}
\hline Gene & Sequence 5'-3' & Length (bp) \\
\hline PCR $a s 3 m t(\mathrm{~F})$ & AGAACCGCTGATAATGGCTCAC & 1119 \\
PCR $a s 3 m t(\mathrm{R})$ & CGTCCTATGATCATTTGCAGCAG & 148 \\
qPCR $a s 3 m t(\mathrm{~F})$ & CGGCTACAAGAAGCCAAACG & \\
qPCR $a s 3 m t(\mathrm{R})$ & TGCTTCAACCAGAACCTGCT & 149 \\
qPCR $a c t b(\mathrm{~F})$ & GATCTGGCATCACACCTTCTACAA & \\
qPCR $a c t b(\mathrm{R})$ & CGTACATGGCAGGAGTGTTGAA & \\
\hline
\end{tabular}

Accession number for qPCR $\beta$-actin (actb) primers, AB182330; $\mathrm{F}$ forward primer, $\mathrm{R}$ reverse primer 
Table 2 Dissolved arsenic concentration ( $\mathrm{ppb}, \mu \mathrm{g} / \mathrm{L})$ and $\mathrm{pH}$ in the studied three sites (BP Bubbling Pond, SR Salt River, WL Willow Lake)

\begin{tabular}{lrrll}
\hline Population & \multicolumn{2}{l}{ Arsenic concentration $(\mathrm{ppb})$} & $\mathrm{pH}$ \\
\cline { 2 - 4 } & Average \pm SD & RSD & \multicolumn{2}{l}{$\begin{array}{l}\text { From Jones et al. (2020) } \\
\text { Mean } \pm \text { SD }\end{array}$} \\
\hline BP & $15.72 \pm 0.22$ & 1.40 & $16.46 \pm 5.9(N=68)$ & 7.46 \\
SR & $3.26 \pm 0.30$ & 9.28 & N/A & 7.73 \\
WL & $1.87 \pm 0.31$ & 16.66 & N/A & 7.27 \\
\hline
\end{tabular}

Average and standard deviations (SD) are calculated from technical replicates for each site. Relative standard deviation (RSD) is the absolute value of the coefficient of variation

DNA ladder (\#N3200, New England BioLabs) to confirm size (Figure S2). The PCR amplicons were excised from the gel and purified using the Monarch DNA gel extraction kit (\#T1020, New England BioLabs) according to manufacturer's instructions. Purified amplicons were submitted to GeneWiz (South Plainfield, NJ) for Sanger sequencing. Twenty-three samples (11 from BP, 12 from WL) were sequenced in both directions and the remaining 35 samples were only sequenced in the reverse direction because adequate sequence coverage ( $872 \mathrm{bp}, 77.9 \%$ of total cDNA sequence) was achieved using the reverse primer only. Sequence chromatograms were visualized and bases were called manually to generate sequences. Sequences were deposited to NCBI's GenBank, accession numbers: MT628704-MT6287078. Sequence polymorphisms were identified as double peaks or deviations from the reference sequence (ENSGAFG00000012739). Sequence alignments were performed in A plasmid Editor (ApE, ver. 2.0.55).

\section{Quantitative PCR}

To investigate potential differences in as $3 m t$ expression among the populations, we conducted quantitative real-time PCR (qPCR) using CFX-Touch 384 real-time thermocycler (BioRad) and SsoAdvanced Universal Inhibitor Tolerant SYBR Green Supermix (\#1725017, BioRad). We selected 8, 8 , and 16 males each from the BP, SR, and WL (including 10 WL SNP-harboring males) sites. We developed forward and reverse primers (Table 1) over the fourth and fifth exons of reference G. affinis as3mt (ENSGAFG00000012739) and also used forward and reverse $a c t b$ ( $\beta$-actin) primers (Table 1 ) as a house-keeping reference gene (Huang et al. 2013, 2014). For the experiment, we isolated DNA-free total RNA from individual fish, previously preserved in TRIzol at $-80^{\circ} \mathrm{C}$, and synthesized cDNA (as stated above). For real-time quantification, cDNA was diluted 1:5 in nuclease-free $\mathrm{H}_{2} \mathrm{O}$ and $6 \mu \mathrm{l}$ reactions were performed in triplicate for each cDNA template (each cDNA template represents one fish). Reaction setup followed manufacturer's instructions, briefly, $1.5 \mu \mathrm{l}$
cDNA template, $3 \mu \mathrm{l} 2 \times$ SYBR Green Supermix, $0.18 \mu \mathrm{l}$ forward and reverse $a s 3 m t$ or $a c t b$ primers $[300 \mathrm{nM}$ final], and $1.32 \mu \mathrm{l}$ DNase-free $\mathrm{H}_{2} \mathrm{O}$ were combined per reaction. Real-time thermocycling was performed according to manufacturer's suggestions, specifically:

1. Initial denaturation/enzyme activation at $98^{\circ} \mathrm{C}$ hold $2 \mathrm{~min}$;

2. $98{ }^{\circ} \mathrm{C}$ for $10 \mathrm{sec}$ denaturation, then $60^{\circ} \mathrm{C}$ for $20 \mathrm{sec}$ annealing, and extension repeated for 40 cycles, fluorescence emission collected concurrently with extension;

3. Melt curve analysis between $65-95^{\circ} \mathrm{C}$ with $0.5{ }^{\circ} \mathrm{C}$ increments at 2-5 sec per step.

For each fish, we repeated the real-time PCR on as $3 m t$ twice with each cDNA template (i.e., biological replicate; $n=8 \mathrm{BP} ; n=8 \mathrm{SR} ; n=16 \mathrm{WL}$ ) amplified in triplicate (i.e., technical triplicates). The graphed values represent the averages from the two runs (except for four fishes from the BP population, which, due to technical reasons were based on the second run only). Notably, for both repeated runs consistent results within treatment groups were observed, and therefore, we concluded that the second BP assay for these fish was sufficient for reliable analysis. Therefore, the $\mathrm{N}$ used for statistical analysis equals the average of the technical replicates (that is, each fish's average across all technical replicates).

\section{Statistics}

To determine the potential difference in the frequency of any as 3mt SNP mutations among BP, SR, and $\mathrm{WL}$, we used the Fisher exact test with Bonferroni correction $(\alpha=0.017)$ as a post-hoc test. To determine the potential difference in as $3 m t$ expression across genotypes, qPCR data were analyzed using an independent sample t-test because the data were normally distributed (Kolmogorov-Smirnov Normality test, $P>0.05$ ). To determine the potential difference in as $3 m t$ expression across populations, qPCR data were analyzed using a Kruskal-Wallis test because the data were not normally distributed (Kolmogorov-Smirnov Normality test, $P<0.05$ ) and the sample size was relatively small. Post-hoc multiple comparisons were then followed by a Bonferroni correction. Statistical analyses were done using SPSSPC (ver. 24.0.0.0, IBM SPSS Statistics) and graphs were drawn with Prism (Version 9.00, Prism Graphpad).

\section{Results}

Water parameters are shown in Table 2. Both WL and SR sites had arsenic levels well below the USEPA drinking 
Table 3 Synonymous single nucleotide polymorphism (SNP) in as3mt of Gambusia affinis, which consists of $1119 \mathrm{bp}$, having 10 exons and 11 introns: two SNPs on exon 4 and one on exon 10, resulting in four different genotypes of TTG, TTC, CCG, CCC

\begin{tabular}{lllll}
\hline Ind \# & \multicolumn{2}{l}{ Nucleotide change (location) } & & Genotype \\
\cline { 2 - 4 } & $\mathrm{T} \rightarrow \mathrm{C}(201)$ & $\mathrm{T} \rightarrow \mathrm{C}(258)$ & $\mathrm{G} \rightarrow \mathrm{C}(909)$ & TTG \\
\hline WL3 & $\mathrm{C}>\mathrm{T}$ & $\mathrm{C}>\mathrm{T}$ & $\mathrm{C}>\mathrm{G}$ & $\mathrm{CCC}$ \\
WL4 & $\mathrm{C}>\mathrm{T}$ & $\mathrm{C}>\mathrm{T}$ & $\mathrm{C}>\mathrm{G}$ & $\mathrm{CCC}$ \\
WL8 & $\mathrm{C}>\mathrm{T}$ & $\mathrm{C}>\mathrm{T}$ & $\mathrm{G}$ & $\mathrm{CCG}$ \\
WL9 & $\mathrm{C}$ & $\mathrm{C}$ & $\mathrm{C}>\mathrm{G}$ & $\mathrm{CCC}$ \\
WL10 & $\mathrm{C}>\mathrm{T}$ & $\mathrm{C}>\mathrm{T}$ & $\mathrm{G}$ & $\mathrm{CCG}$ \\
WL13 & $\mathrm{C}>\mathrm{T}$ & $\mathrm{C}>\mathrm{T}$ & $\mathrm{C}>\mathrm{G}$ & $\mathrm{CCC}$ \\
WL17 & $\mathrm{T}>\mathrm{C}$ & $\mathrm{T}>\mathrm{C}$ & $\mathrm{C}>\mathrm{G}$ & $\mathrm{TTC}$ \\
WL18 & $\mathrm{C}$ & $\mathrm{C}$ & $\mathrm{C}>\mathrm{G}$ & $\mathrm{CCC}$ \\
WL20 & $\mathrm{C}>\mathrm{T}$ & $\mathrm{C}>\mathrm{T}$ & $\mathrm{G}$ & $\mathrm{CCG}$ \\
WL27 & $\mathrm{T}>\mathrm{C}$ & $\mathrm{T}>\mathrm{C}$ & $\mathrm{C}>\mathrm{G}$ & $\mathrm{TTC}$ \\
WL31 & $\mathrm{T}>\mathrm{C}$ & $\mathrm{T}>\mathrm{C}$ & $\mathrm{C}>\mathrm{G}$ & TTC \\
\hline
\end{tabular}

water limit of $10 \mathrm{ppb}(\mu \mathrm{g} / \mathrm{L})$ as $1.87 \mathrm{ppb}$ and $3.26 \mathrm{ppb}$, respectively. However, the water from BP site had arsenic levels of $15.72 \mathrm{ppb}$ between 3 and 9 times the levels of the other two sites. The BP site was consistent with previously reported arsenic levels from nearby sites (extracted from data used in Jones et al. 2020); there were no publicly available or published results directly linked to surface water resources in or near the other two sites for comparison. We did not probe for any other potential contaminants in the water samples; and environmental factors such as water temperature were not compared because fishes were collected at different times of year.

Eleven out of $24 \mathrm{WL}$ fishes (45.8\%), had silent single nucleotide polymorphisms at three different locations in the as $3 m t$ coding sequence (Table 3). Relative to the reference sequence we observed, nucleotide changes from $\mathrm{T}$ to $\mathrm{C}$ occurred at nucleotide location 201/1119 and 258/1119 on exon 4 and from $G$ to $C$ at nucleotide location $909 / 1119$ on exon 10 (Figure S3). Three fish did not have the point mutation at the 909 residue; and two fish were homozygotic $\mathrm{C}$ at the 201 and 258 residues. The rest of the mutations were all heterozygotic. Unlike fish from the WL population, no fish had any SNPs from BP and SR populations. The occurrence of any as 3mt SNP mutations was significantly different among the three populations. Specially, the frequency in WL was greater than that in either BP or SR (Fisher exact test, $P<0.001$ ).

The expression of as $3 m t$ mRNA, normalized to the expression of actb mRNA, was not different between WL fish with (WLM) and without (WL) SNPs $(t=0.636$; $P=0.535$, Fig. 3A). A significant difference in as $3 m t$ expression was found among BP, SR, and WL sites (Kruskal Wallis statistic $=11.60, \quad \mathrm{df}=2, \quad P=0.003$, Fig. 3B). Specifically, the expression of as $3 m t$ mRNA of
A
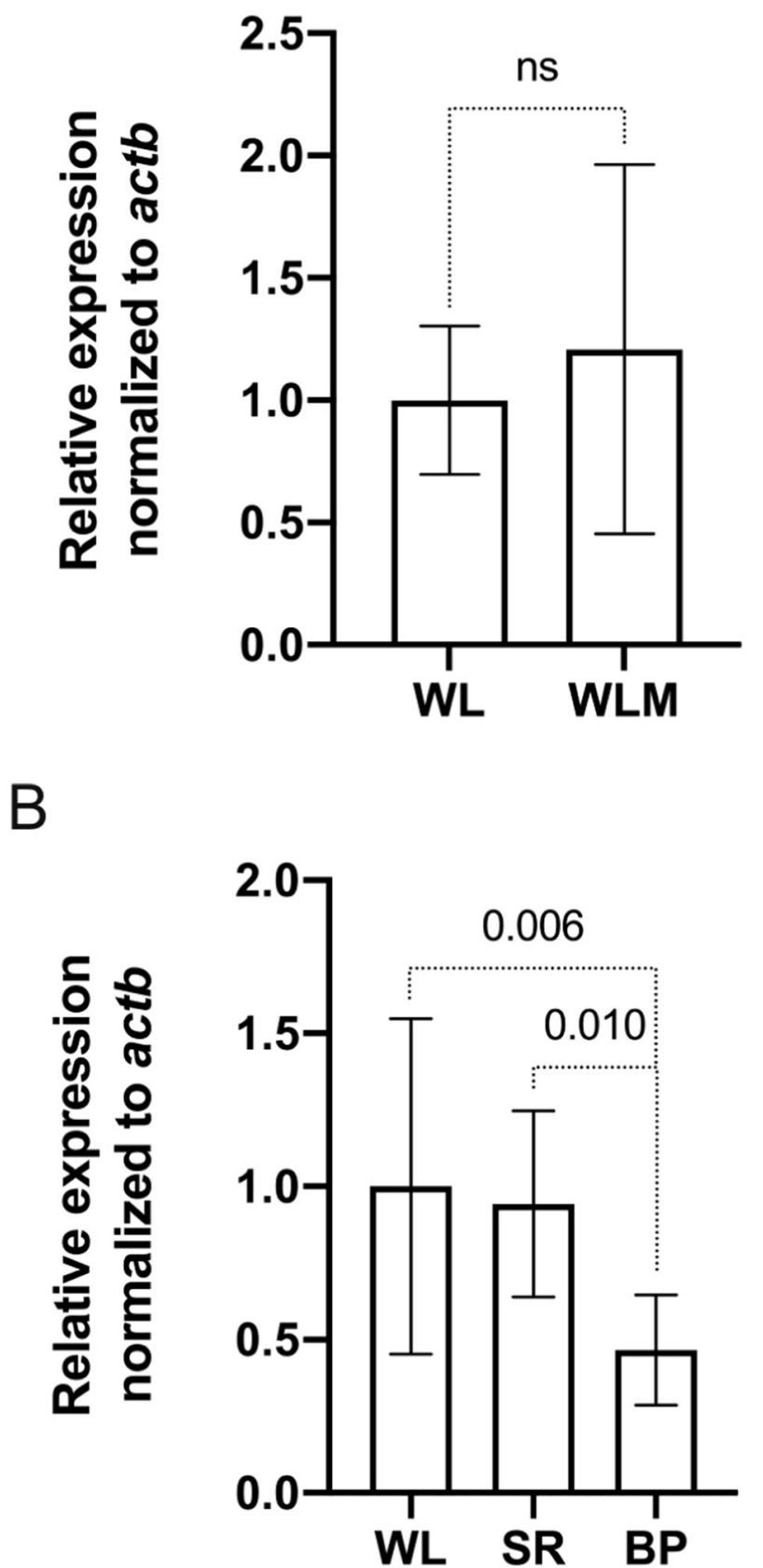

Fig. 3 Gene expression of as3mt in Western mosquitofishes (Gambusia affinis) normalized to actb transcript levels. A as $3 m t$ transcript levels in single-nucleotide polymorphic WL fish (WLM) relative to normal WL fish compared by an independent sample $t$ test; (B) and as 3mt transcript levels in SR and BP fish relative to WL compared by a Kruskal-Wallis test with post-hoc multiple comparisons. Mean and standard deviation are plotted. $P$ values are shown above the horizontal lines

BP was approximately $50 \%$ lower than that of SR and WL ( $P=0.01, P=0.006$, respectively). While, the expression level between SR and WL mRNA was not different $(P>0.05)$ (Fig. 3B). 


\section{Discussion}

\section{Allelic frequency}

To our knowledge, this study provides the first report of any SNP's in as $3 m t$ in any vertebrate wildlife species. We found three exonic SNPs on G. affinis as $3 m t$ in this study. Those SNPs have not been previously reported in humans, and this is the first report of an SNP on exon 4 (Wood et al. 2006; Fujihara et al. 2010; Schlebusch et al. 2013; Antonelli et al. 2014; Agusa et al. 2015; Apata and Pfeifer 2020). Interestingly, the three exonic SNPs in G. affinis as $3 m t$ found in this study are all synonymous SNPs unlike known human exonic SNPs (Wood et al. 2006). In human populations exposed to high arsenic concentrations over many generations, the frequency of protective mutations is often higher than those seen in populations living with lower levels of exposure, and differences in relative urinary production of MMA and DMA is a representative phenotype of AS3MT SNP variation and alterations in enzyme methylation activity (Engström et al. 2007, 2011; Watanabe and Hirano 2013; Antonelli et al. 2014; Apata and Pfeifer 2020). For example, women from populations where water resources contain high arsenic concentrations exhibit populationspecific $A S 3 M T$ haplotypes; the haplotypes differ in whether they lead to a higher percentage of MMA or DMA in urine samples (Engström et al. 2011). Other findings in humans, however, show that many other AS3MT SNPs identified are neutral, and do not affect detoxification of arsenic (Antonelli et al. 2014). To test the hypotheses that SNPs in the expressed G. affinis as $3 m t$ gene function to increase arsenictolerance, we propose analyzing whole fish arsenic metabolites such as inorganic arsenic, MMA, and DMA from fish with identified differences in SNPs. In addition, verifying more mutations from other non-coding regions of as $3 m t$ and any potential negative symptoms in morphology and behavior in those SNP G. affinis would be worthwhile.

In contrast to our original hypothesis, we found SNPs in as $3 m t$ among mosquitofish collected from the lowest arsenic contamination level sites. It is possible that the haplotype in the G. affinis population from the higher arsenic concentration sites might be adaptive to the high and medium arsenic environments after its initial introduction to the sites, which could result in no SNPs. It is also possible that the G. affinis populations in low arsenic water are more tolerant to random mutations because the gene is not under strong selective pressure.

The as $3 m t$ sequence, also obtained from both BP and SR fishes, is highly conserved across vertebrates including Danio rerio and the methyltransferase domain of the as $3 m t$ has high sequence overlap to parts of functional human AS3MT sequences (Palmgren et al. 2017) (Fig. S1). These results imply that $G$. affinis as $3 m t$ alleles identified from BP and SR in this study might code for gene products that are functionally efficient in terms of arsenic methylation. Recent studies have found that adaptive mutations occur rapidly in response to chemical (natural and artificial) exposure and lead to local microevolutionary outcomes (Hamilton et al. 2017; Gouin et al. 2019) support this interpretation. Because two of our study populations had gene sequences similar to each other and to the zebrafish genome, our results suggest that SNPs identified in the Willow Lake population occurred over the relatively short period since their introduction to this region (Dees 1961; Miller and Lowe 1967) and future studies can investigate whether these differences in as $3 m t$ haplotypes provide protection against the toxic effects of arsenic exposure.

\section{as3mt expression}

Gambusia affinis expressed as $3 m t$ at the same levels independently of genotype, suggesting that these SNPs do not decrease or increase as $3 m t$ expression. Furthermore, the synonymous nature of the SNPs would be unlikely to change protein properties. This expression level of as $3 m t$ may be sufficient to provide a protective phenotype, especially in a low arsenic environment such as was found in this population. In humans, increased as $3 m t$ expression is more evident when SNPs were deleterious, presumptively as a compensatory mechanism (Engström et al. 2011). Lastly, SNPs might affect overall as $3 m t$ functions through post-transcriptional processes rather than through gene transcription. In human MDRI (multidrug resistance 1), silent SNPs post-transcriptionally affected timing of cotranslational folding, resulted in altered structure of substrate and inhibitor interaction sites (Kimchi-Sarfaty et al. 2007). In humans, nonsynonymous as $3 m t$ SNPs also changed arsenic-affinity and stability of as $3 m t$ through conformational structure changes of proteins, but not by changing gene expression ( $\mathrm{Li}$ et al. 2017).

Mosquitofish as $3 m t$ expression was significantly lower in the site containing the highest arsenic concentrations, which was opposite to our initial expectation. This result suggests as $3 m t$ expression in $G$. affinis at this site might be under control of upstream regulatory processes. For example, in humans, DNA-methyltransferase is directly linked with as $3 m t$ expression (Engström et al. 2011). Also, we have not evaluated the promotor region of the gene for fish from these populations. Nevertheless, this lower as $3 m t$ expression in BP population compared to the $\mathrm{WL}$ and SR populations living in waters with lower arsenic concentrations suggests fish in BP population may exhibit signs of toxicity. Future studies will test the ratio of whole-body MMA/DMA in fish from these populations, investigate whether there are SNPs in the promotor region of as $3 m t$, and evaluate these populations for other arsenic-related morphological characteristics such as curved spines (Gonzalez et al. 2010; Sun et al. 2016). 


\section{Conclusion}

In summary, this preliminary study provides the first evidence of sequence variation in as $3 m t$ in a wildlife population and has several interesting implications for the evolution of toxic responses in wildlife. We found significantly different SNP frequency in as $3 m t$ across different arsenic-exposure populations of Western mosquitofish, but as $3 m t$ expression was not different between normal and SNP carrying fishes. The results were not consistent with our original hypothesis that $G$. affinis exposed to high arsenics could show greater SNP frequency and higher as $3 m t$ expression. Future studies will determine whether there are morphological arsenic-related symptoms across populations. In addition, future studies could evaluate mutations in both the promotor and intron regions of as $3 \mathrm{mt}$. Because of their wide global distribution, Western mosquitofish may prove to be a good model to study the complexity of microevolutionary processes in response to arsenic exposure.

\section{Data availability}

Sequences obtained herein have been deposited to NCBI. Collecting sites for mosquitofish have been identified.

Acknowledgements We would like to thank Alejandro Grajal-Puche for helping with water sampling, Jonathan Credo and Jani Ingram for performing ICPMS measurements, and Rebecca Helm for providing critical feedback on manuscript preparation. We are very grateful for research support coming Kangwon National University in 2018 (DP), Arizona Technology Research Initiative Fund (MCS) and the Southwest Health Equities Research Collaborative, National Institutes of Health \#U54MD012388 (MCS, CRP).

Authors contributions DP, CRP. and MCS designed the study, performed the experiments, analyzed the data and wrote the manuscript. Wang helped revise the manuscript and performed sequence alignments.

Funding These studies were supported by research and/or equipment funds from Kangwon National University in 2018 (DP), Arizona Technology Research Initiative Fund (MCS), Southwest Health Equities Research Collaborative, National Institutes of Health \#U54MD012388 (MCS, CRP), and the Northern Arizona University, Department of Biological Sciences Wolff Award (GW).

\section{Compliance with ethical standards}

Conflict of interest The authors declare no competing interests.

Ethics approval Animal studies were reviewed and approved by Northern Arizona University's Institutional Animal Care and Use Committee.

Consent for publication DP, CRP, GW, and MCS consent to publication.

Publisher's note Springer Nature remains neutral with regard to jurisdictional claims in published maps and institutional affiliations.
Open Access This article is licensed under a Creative Commons Attribution 4.0 International License, which permits use, sharing, adaptation, distribution and reproduction in any medium or format, as long as you give appropriate credit to the original author(s) and the source, provide a link to the Creative Commons license, and indicate if changes were made. The images or other third party material in this article are included in the article's Creative Commons license, unless indicated otherwise in a credit line to the material. If material is not included in the article's Creative Commons license and your intended use is not permitted by statutory regulation or exceeds the permitted use, you will need to obtain permission directly from the copyright holder. To view a copy of this license, visit http://creativecommons. org/licenses/by/4.0/.

\section{References}

Agusa T, Kunito T, Minh Tue N et al. (2015) Relationship between arsenic ( +3 oxidation state) methyltransferase genetic polymorphisms and methylation capacity of inorganic arsenic. Nihon Eiseigaku Zasshi 70:186-196. https://doi.org/10.1265/jjh.70.186

Antonelli R, Shao K, Thomas DJ et al. (2014) AS3MT, GSTO, and PNP polymorphisms: Impact on arsenic methylation and implications for disease susceptibility. Environ Res 132:156-167. https://doi.org/10.1016/j.envres.2014.03.012

Apata M, Pfeifer SP (2020) Recent population genomic insights into the genetic basis of arsenic tolerance in humans: the difficulties of identifying positively selected loci in strongly bottlenecked populations. Heredity (Edinb) 124:253-262. https://doi.org/10. 1038/s41437-019-0285-0

Bambino K, Zhang C, Austin C, et al. (2018) Inorganic arsenic causes fatty liver and interacts with ethanol to cause alcoholic liver disease in zebrafish. Dis Model Mech 11: https://doi.org/10.1242/ dmm.031575

Bortone SA, Davis WP (1994) Fish intersexuality as indicator of environmental stress. Bioscience 44:165-172. https://doi.org/10. 2307/1312253

Boyle D, Brix KV, Amlund $\mathrm{H}$ et al. (2008) Natural arsenic contaminated diets perturb reproduction in fish. Environ Sci Technol 42:5354-5360. https://doi.org/10.1021/es800230w

Carlin DJ, Naujokas MF, Bradham KD et al. (2016) Arsenic and environmental health: State of the science and future research opportunities. Environ Health Perspect 124:890-899. https://doi. org/10.1289/ehp.1510209

Coryell M, McAlpine M, Pinkham NV et al. (2018) The gut microbiome is required for full protection against acute arsenic toxicity in mouse models. Nat Commun 9:1-9. https://doi.org/10.1038/ s41467-018-07803-9

Credo J, Torkelson J, Rock T, Ingram J (2019) Quantification of Elemental Contaminants in Unregulated Water across Western Navajo Nation. Int J Environ Res Public Health. 16:2727-2742. https://doi.org/10.3390/ijerph16152727

Dees LT (1961) The Mosquitofish, Gambusia affinis. Fish Leafl 525:1-6

Dlugosch KM, Parker IM (2008) Founding events in species invasions: Genetic variation, adaptive evolution, and the role of multiple introductions. Mol Ecol 17:431-449. https://doi.org/10. 1111/j.1365-294X.2007.03538.x

Drobna Z, Naranmandura H, Kubachka KM et al. (2009) Disruption of the arsenic $(+3$ oxidation state) methyltransferase gene in the mouse alters the phenotype for methylation of arsenic and affects distribution and retention of orally administered arsenate. Chem Res Toxicol 22:1713-1720. https://doi.org/10.1021/tx900179r

Engström K, Vahter M, Mlakar SJ et al. (2011) Polymorphisms in arsenic $(+$ III oxidation state) methyltransferase (AS3MT) predict gene expression of AS3MT as well as arsenic metabolism. 
Environ Health Perspect 119:182-188. https://doi.org/10.1289/ ehp. 1002471

Engström KS, Broberg K, Concha G et al. (2007) Genetic polymorphisms influencing arsenic metabolism: Evidence from Argentina. Environ Health Perspect 115:599-605. https://doi.org/ 10.1289/ehp.9734

Fujihara J, Soejima M, Yasuda T et al. (2010) Global analysis of genetic variation in human arsenic (+3 oxidation state) methyltransferase (AS3MT). Toxicol Appl Pharmacol 243:292-299. https://doi.org/10.1016/j.taap.2009.11.020

Gonzalez HO, Hu J, Gaworecki KM et al. (2010) Dose-responsive gene expression changes in juvenile and adult mummichogs (Fundulus heteroclitus) after arsenic exposure. Mar Environ Res 70:133-141. https://doi.org/10.1016/j.marenvres.2010.04.003

Gouin N, Bertin A, Espinosa MI, et al (2019) Pesticide contamination drives adaptive genetic variation in the endemic mayfly Andesiops torrens within a semi-arid agricultural watershed of Chile. Environ Pollut 255: https://doi.org/10.1016/j.envpol.2019.113099

Hallauer J, Geng X, Yang H-C et al. (2016) The effect of chronic arsenic exposure in zebrafish. Zebrafish 13:405-412. https://doi. org/10.1089/zeb.2016.1252

Hamdi M, Yoshinaga M, Packianathan C et al. (2012) Identification of an S-adenosylmethionine (SAM) dependent arsenic methyltransferase in Danio rerio. Toxicol Appl Pharmacol 262:185-193. https://doi.org/10.1016/j.taap.2012.04.035

Hamilton PB, Rolshausen G, Uren Webster TM, Tyler CR (2017) Adaptive capabilities and fitness consequences associated with pollution exposure in fish. Philos Trans R Soc B Biol Sci 372: https://doi.org/10.1098/rstb.2016.0042

Huang GY, Ying GG, Liang YQ et al. (2014) Expression patterns of metallothionein, cytochrome P450 1A and vitellogenin genes in western mosquitofish (Gambusia affinis) in response to heavy metals. Ecotoxicol Environ Saf 105:97-102. https://doi.org/10. 1016/j.ecoenv.2014.04.012

Huang GY, Ying GG, Liang YQ et al. (2013) Hormonal effects of tetrabromobisphenol A using a combination of in vitro and in vivo assays. Comp Biochem Physiol - C Toxicol Pharmacol 157:344-351. https://doi.org/10.1016/j.cbpc.2013.03.003

Hughes MF, Beck BD, Chen Y et al. (2011) Arsenic exposure and toxicology: A historical perspective. Toxicol Sci 123:305-332. https://doi.org/10.1093/toxsci/kfr184

Hunt SE, McLaren W, Gil L et al. (2018) Ensembl variation resources Database (Oxford) 1-12. https://doi.org/10.1093/database/bay119

Jones MC, Credo JM, Ingram JC et al. (2020) Waters across Arizona including native lands. J Contemp Water Res Educ 169:44-60

Khairul I, Wang QQ, Jiang YH et al. (2017) Metabolism, toxicity and anticancer activities of arsenic compounds. Oncotarget 8:23905-23926. https://doi.org/10.18632/oncotarget.14733

Kimchi-Sarfaty C, Oh JM, Kim IW et al. (2007) A "silent" polymorphism in the MDR1 gene changes substrate specificity. Science (80-) 315:525-528. https://doi.org/10.1126/science.1135308

Koch I, Zhang J, Button M et al. (2015) Arsenic $(+3)$ and DNA methyltransferases, and arsenic speciation in tadpole and frog life stages of western clawed frogs (Silurana tropicalis) exposed to arsenate. Metallomics 7:1274-1284. https://doi.org/10.1039/c5mt00078e

Li J, Packianathan C, Rossman TG, Rosen BP (2017) Nonsynonymous polymorphisms in the human AS3MT arsenic methylation gene: Implications for arsenic toxicity. Chem Res Toxicol 30:1481-1491. https://doi.org/10.1021/acs.chemrestox.7b00113

Miller R, Lowe C (1967) Fishes of Arizona. In: Lowe C (ed) The vertebrates of Arizona. The University of Arizona Press, pp $133-151$
Minatel BC, Sage AP, Anderson C et al. (2018) Environmental arsenic exposure: From genetic susceptibility to pathogenesis. Environ Int 112:183-197. https://doi.org/10.1016/j.envint.2017.12.017

Oziolor EM, Reid NM, Yair S et al. (2019) Adaptive introgression enables evolutionary rescue from extreme environmental pollution. Science (80-) 364:455-457. https://doi.org/10.1126/science. aav4155

Palmgren M, Engström K, Hallström BM et al. (2017) AS3MTmediated tolerance to arsenic evolved by multiple independent horizontal gene transfers from bacteria to eukaryotes. PLoS One 12:1-22. https://doi.org/10.1371/journal.pone.0175422

Park D, Minor M, Propper C (2004) Toxic response of endosulfan to breeding and non-breeding female mosquitofish. J Environ Biol 25:119-124

Reid NM, Proestou DA, Clark BW et al. (2016) The genomic landscape of rapid repeated evolutionary adaptation to toxic pollution in wild fish. Science (80-) 354:1305-1308. https://doi.org/10. 1126/science.aah4993

Schlebusch CM, Gattepaille LM, Engström K et al. (2015) Human adaptation to arsenic-rich environments. Mol Biol Evol 32:1544-1555. https://doi.org/10.1093/molbev/msv046

Schlebusch CM, Lewis CM, Vahter M et al. (2013) Possible positive selection for an arsenic-protective haplotype in humans. Environ Health Perspect 121:53-58. https://doi.org/10.1289/ ehp. 1205504

Stýblo M, Douillet C, Bangma J et al. (2019) Differential metabolism of inorganic arsenic in mice from genetically diverse collaborative cross strains. Arch Toxicol 93:2811-2822. https://doi.org/10. 1007/s00204-019-02559-7

Sun HJ, Xiang P, Tang MH et al. (2016) Arsenic impacted the development, thyroid hormone and gene transcription of thyroid hormone receptors in bighead carp larvae (Hypophthalmichthys nobilis). J Hazard Mater 303:76-82. https://doi.org/10.1016/j.jha zmat.2015.10.032

Turner CL (1942) A quantitative study of the effects of different concentrations of ethynyl testosterone and methyl testosterone in the production of gonopodia in females of Gambusia affinis. Physiol Zool 15:263-280. https://doi.org/10.1086/physzool.15.3.30151640

Valenzuela OL, Drobná Z, Hernández-Castellanos E et al. (2009) Association of AS3MT polymorphisms and the risk of premalignant arsenic skin lesions. Toxicol Appl Pharmacol 239:200-207. https://doi.org/10.1016/j.taap.2009.06.007

Watanabe T, Hirano S (2013) Metabolism of arsenic and its toxicological relevance. Arch Toxicol 87:969-979. https://doi.org/ 10.1007/s00204-012-0904-5

Waters SB, Devesa V, Del Razo LM et al. (2004) Endogenous reductants support the catalytic function of recombinant rat cyt19, an arsenic methyltransferase. Chem Res Toxicol 17:404-409. https://doi.org/10.1021/tx0342161

Wood TC, Salavagionne OE, Mukherjee B et al. (2006) Human arsenic methyltransferase (AS3MT) pharmacogenetics: gene resequencing and functional genomics studies. J Biol Chem 281:7364-7373. https://doi.org/10.1074/jbc.M512227200

Ye J, Chang Y, Yan Y et al. (2014) Identification and characterization of the arsenite methyltransferase from a protozoan, Tetrahymena pyriformis. Aquat Toxicol 149:50-57. https://doi.org/10.1016/j. aquatox.2014.01.028

Zhang W, Huang L, Wang WX (2012) Biotransformation and detoxification of inorganic arsenic in a marine juvenile fish Terapon jarbua after waterborne and dietborne exposure. J Hazard Mater 221-222:162-169. https://doi.org/10.1016/j.jha zmat.2012.04.027 